\title{
Oestrogen plus progestin increased venous thromboembolic disease in postmenopausal women with coronary artery disease
}

\author{
Grady D, Wenger NK, Herrington D, et al for the Heart and Estrogen/progestin Replacement Study Research Group. \\ Postmenopausal hormone therapy increases risk for venous thromboembolic disease. The Heart and Estrogen/progestin \\ Replacement Study. Ann Intern Med 2000 May 2;132:689-96.
}

\section{QUESTION: Does oestrogen plus progestin increase the risk of venous thromboembolic events in postmenopausal women with established coronary artery disease (CAD)?}

\author{
Source of funding: \\ Wyeth-Ayerst \\ Laboratories. \\ For correspondence: \\ Dr D Grady, University \\ of California, San \\ Francisco, 74 New \\ Montgomery Street, Suite \\ 600, San Francisco, CA \\ 94105, USA. Fax +1 \\ 4153864044.
}

\section{Conclusion}

Oestrogen plus progestin increased the risk of venous tors, patients, outcome assessors), placebo controlled trial with mean follow up of 4.1 years (Heart and Estrogen/progestin Replacement Study [HERS]).

\section{Setting}

20 clinical centres in the US.

\section{Patients}

2763 postmenopausal women $<80$ years of age (mean age $67 \mathrm{y}, 89 \%$ white) with established CAD but no previous venous thromboembolism and who had not had a hysterectomy. Exclusion criteria were $\mathrm{CAD}$ event $\leq 6$ months or hormone use $\leq 3$ months before entry, venous thromboembolism, breast cancer, endometrial cancer, uncontrolled hypertension, diabetes, or other fatal disease. Follow up was $98 \%$.

\section{Intervention}

1380 women were allocated to hormone replacement therapy (HRT) of conjugated equine estrogens, $0.625 \mathrm{mg}$, plus medroxyprogesterone acetate, $2.5 \mathrm{mg}$ once/day; 1383 women were allocated to placebo.

\section{Main outcome measures}

Deep venous thrombosis or pulmonary embolism.

\section{Main results}

Analysis was by intention to treat. 34 women $(2.5 \%)$ who received HRT and $13(0.9 \%)$ who received placebo had a venous thromboembolic event (relative hazard 2.7, 95\% CI 1.4 to 5.0, $\mathrm{p}=0.003$ ) (table). Women who received HRT had higher rates of deep venous thrombosis $(p=0.008)$ and non-idiopathic venous thromboembolic events $(p=0.01)$ than women who received placebo (table); no differences existed between groups for pulmonary embolism $(\mathrm{p}=0.08)$ or idiopathic thromboembolic events $(p=0.09)$ (table). with established coronary artery disease.

*Information provided by author.
Controversy continues over the nature and extent of the risks of hormone therapy in women, whether used as an oral contraceptive or HRT. The differences of scientific opinion, however, as to the risks and benefits of hormone therapies, arise largely from he difficulty in interpreting studies that are limited by methodological problems.

This well designed, randomised, triple blind, placebo controlled trial by Grady et al provides convincing evidence that women with established CAD who take HRT (specifically oestrogen plus progestin) after menopause have an increased risk of venous thromboembolic disease. At a mean follow up of 3.3 years, the investigators notified participants to discontinue study medications in situations associated with increased risk for venous thromboembolism, such as surgery, admission to hospital, fracture, and cancer. Among women in the study, treating 66 women with CAD for 1 year would result in 1 additional venous thromboembolic event. The findings confirm those of previous studies, concluding that the increased risk was most likely related to the oestrogen component of hormone therapy.

This study supports women's health advocates who, over the past 50 years, have cautioned women of all ages against indiscriminate use of hormone therapy. ${ }^{2}$ Health practitioners are therefore challenged to weigh the benefits and risks when advising postmenopausal women with CAD about the use of HRT. It is clear from this study that women with any risk factors (eg, cancer, cardiovascular disease, lower extremity fracture, or immobilisation for any reason) should not take HRT. If a woman decides that the benefits outweigh the risks, then she needs to be advised on how to prevent thromboembolic disease (eg, increasing mobility). Health practitioners and women also need to be informed of nutritional alternatives to HRT, which are currently still under investigation, and other related current issues. ${ }^{34}$

Lynne S Giddings, RGON, RM, PhD Associate Professor, Faculty of Health Studies Auckland University of Technology Auckland,Aotearoa/New Zealand

Lobo RA. (Ed). Treatment of the postmenopausal woman: basic and clinical aspects (Second edition). Philadelphia, PA: Lippincott Williams \& Wilkins, 1999 land, NZ: Penguin Books, 1991.

3 Keller C, Fullerton J, Mobley C. Supplemental and complementary alternatives to hormone replacement therapy. J Am Acad Nurse Pract 1999;11:187-98.

4 Jacobowitz RS. The estrogen answer book. New York: Little, Brown and Company, 1999
2 Coney S. The menopause industry: a guide to medicine's "discovery" of the mid-life woman. Auck-

Hormone replacement therapy (HRT) v placebo in postmenopausal women with established coronary artery diseaset

\begin{tabular}{llll} 
Outcomes at mean 4.1 years & HRT & Placebo & RRI (95\% CI) \\
Any venous thromboembolic event & $2.5 \%$ & $0.9 \%$ & $162 \%(40$ to 390$)$ \\
\hline Deep venous thrombosis & $1.8 \%$ & $0.7 \%$ & $178 \%(33$ to 484$)$ \\
\hline Non-idiopathic venous thromboembolic event & $1.8 \%$ & $0.7 \%$ & $151 \%(23$ to 412$)$ \\
\hline Pulmonary embolism & $0.8 \%$ & $0.3 \%$ & $176 \%(-7$ to 718$)$ \\
\hline Idiopathic venous thromboembolic event & $0.7 \%$ & $0.2 \%$ & Not significant \\
\hline
\end{tabular}

†Abbreviations defined in glossary; RRI, $\mathrm{NNH}$, and $\mathrm{Cl}$ calculated from data in article. 